\title{
Remembering J. Krishnamurti in the Age of Conflict and Disintegration
}

\author{
Arti Nirmal
}

\begin{abstract}
The views of Jiddu Krishnamurti become highly pertinent in the present age of conflict, chaos and crisis. He observes that our tendency to remain conditioned to 'things known' is the primary cause of every conflict. Hence, 'freedom from the known' is a pre-requisite to avoid conflict and thereby achieve peace. He offers an anti-foundational approach to the entire process of perceiving this world because 'we are the world'. In his philosophy we notice an emphasis on the 'right kind of education' which can be an effective means to resolve conflicts around us. This paper is an attempt to understand the causes of conflict and disintegration in the present age with reference to the philosophy of J. Krishnamurti and also seek measures to resolve it.
\end{abstract}

Index Terms - Choiceless awareness, inward transformation, right education, total awareness.

\section{INTRODUCTION}

Jiddu Krishnamurti is one of those modern seers, thinkers, teachers, reformers and philosophers who define education in highly revolutionized manner. He perceives the modern world in serious crisis and therefore proposes 'the right education' which means an essential awakening of the soul within. $\mathrm{He}$ diagnoses that the fundamental cause of all crisis is our conditioned mind which prevents us from "choiceless awareness". Therefore, education should be such that it can liberate the learners from all sorts of traditional bondage and dogmas. With this view he inspires us to begin 'a quest within the soul' in order to understand the entire process of one's own consciousness.

Paradoxically, we seem to progress outwardly whereas inwardly we are being pushed back to primitiveness due to our over reliance on materialism and consumerism. The loss of faith in true religion and human values has generated doubt, conflict, division and violence in the present age. Thus the 'maladies of modern age' put a big question before us: How to bring about a radical revolution in human living in the world, so confused, so miserable, and at war? This question I think finds its most appropriate answer in the suggestions of Krishnamurti who asks us to begin "a quest within the soul" because "we are the world" [1].

\section{The AgE OF CRISIS, DIVISION AND CONFUSION}

J. Krishnamurti, the true seeker of knowledge, examines the world very keenly and traces a crisis of values, trust and

Manuscript received March 28, 2016; revised September 16, 2016.

Arti Nirmal is with Banaras Hindu University, India (e-mail: artinirmalbhu@gmail.com). confidence because "the lack of comprehension of ourselves is creating havoc in the world, in spite of all the universities" [2]. He considers that the intellectual obsession in the modern age has brought a problem of human relationship. And it is ridiculous that we are seeking solution to our emotional problems through intellectual measures that do nothing except dividing people. It raises a question that why despite all our worldly progress and mission of civilization, we are failing to become human beings in real sense of the term. Krishnamurti offers pertinent answer to this question by saying that "As long as education doesn't cultivate an integrated outlook in life, it has very little significance" [3]. What we call education today is only acquisition of knowledge, not learning because it has a quality of bondage and learning is never bondage. True learning according to him is a movement towards oneself; that oneself which is living, moving and dynamic in nature.

Krishnamurti differentiates between knowledge and intelligence. In his view "Intelligence is not knowledge. Knowledge gives you capacity, position, status, but knowledge is not love, knowledge is not compassion" [4]. True, the modern education system emphasizes only on the cognitive aspect of human personality by blindly neglecting the affective and psychomotor domains. Thus, the lack of integration among mind, body and heart is the major cause of modern crisis which demands an urgent attention.

\section{EdUCATIONAL PHILOSOPHY OF J. KRISHNAMURTI}

Education, for him is a practice to enquire "as human beings what are we?" [5] It is due to the lack of this practice that our education is making us shallow day by day and we are unable to explore the deeper layers of our being. We are growing disharmonious each day because we try to equate learning with its price in some way. Krishnamurti says that 'wisdom is not marketable'; it 'comes with the abnegation of the self' [6]: 'Knowledge is necessary, science has its place; but if the mind and heart are suffocated by knowledge, and if the cause of suffering is explained away, life becomes vain and meaningless" [7]. The purpose of education is to solve the human problem and the problem of relationship. And if it cannot do that, then education has no meaning. Intellectual training cannot help us in true perception because it causes chaos and violence. To quote the words of Krishnamurti: "You are educated- whatever that word may mean- which is merely cultivating little corner of the vast field of existence. And from that little corner you think you are going to solve all problems, and therefore you disregard totally the rest of the field... So knowledge is essential, but it becomes a complete hindrance when thought, functioning from the past which is 
knowledge, operates....knowledge is necessary, but yet you see that knowledge in human relationship creates conflict" [8].

The field of life is very vast and intricately builds on the pillars of human relationships. But knowledge kills love and stops us from concerning for our relatives and neighbours. "We keep the two-external world and the inwards life of daily travail-completely separate. [We] may be great technicians, have excellent theories about human nature, but all that is the movement of memory and knowledge and has nothing whatsoever to do with [our] daily behavior" [9].

If we contemplate intensively on the question of significance of human life in modern times, then we find that the human life is being redefined in a highly mechanical and commercial fashion. Modern man is spiritually dis-oriented and this leads to fear, fear which divides, and division that causes conflict. Thus, "this crisis cannot be done away with by doctoring with the mind in the forms of psychoanalysis, organized religion, moral rearment (sic), so called better education or by raising the material standard of living. It is mutation, a complete breaking away from any pattern of the past...." [10] Martin Heidegger, too, draws our attention to this division and fear when says "we are living in world of negative peace in the shadow of terror imposed by technology, consumerism, and in contemporary times, political and religious fanaticism' [11].

Krishnamurti contends, "we have come to a point in history where we have to create a new culture, not based on consumerism and industrialization, but a culture based on a real quality of religion" [12]. By religion, he doesn't mean Christianity, Hinduism, Islam or Buddhism. He advocates a secular dictum because every division to him leads to destruction and prevents us from building a new civilization. Therefore, he says: "No book will teach you about it, not the Gita, the Upanishads, the Koran or the Bible, because books are vague, however sacred they are. So you have to go into yourself, but you must not dig too deep a hole... the inquiry into oneself demands great delicacy" [13]. Religion for him is spirituality that entails a "pathless way". It involves seeing the world inside the self in a wordless, conceptless and a totally detached manner. Most importantly, it is through silence and inward gazing rather than verbal talking that the genuine self discovery proceeds.

Krishnamurti considers education as a great force in social amelioration. Education, for him, is a way of living; living silently with love. This living silently is the source of true joy. But this joy can be eternal only if it is indescribable. He tells"... with the very utterance of the word 'I am happy' the experience of happiness is shattered. Thus in enjoyment, there is no enjoyer... There can be no greater renunciation than the removal of the very entity that calls itself the renouncer. It is only when the enjoyer is absent that intense experience of enjoyment is possible" [14]. Unfortunately, we are too much preoccupied with our problems, our ambitions and pursuit of worldly success that we never take time to enjoy looking at naturally beautiful things. We never take time to explore the great mysteries of life which has a joy and romance of its own. He says that we have created this world but "the world we have created is so superficial, so artificial, so ugly if one looks behind the curtain; and we decorate the curtain, hoping that everything will somehow come right" [15]. This superficiality is the major cause of modern crisis. Krishnamurti diagnoses following reasons as the cause of disintegration worldwide:

1) Too much dependence on authority, governance and leadership,

2) We want things to continue as they are with only superficial modifications,

3) We seek peace through ideology and legislation,

4) We do not free ourselves from dogmas and antagonisms,

5) We have a tendency to conform to certain group, community or sect.

These factors not only cause disintegration in human society but also destroy peace which is necessary for human progress in real sense of the term. He, therefore, suggests, "We must realize that as long as we cling to security, as long as we are conditioned by dogmas, there will be strife and misery both within ourselves and in the world" [16].

Krishnamurti finds solution to every problem in 'right education' which motivates us to inquire. 'Right education helps the individual to become highly sensitive to everything... because the highest form of sensitivity is the highest form of intelligence'. Moreover, "Learning is never cumulative, it is a movement of knowing which has no beginning and no end" [17]. Therefore, an educated mind is 'one that looks, watches, listens and feels' and the right kind of education aims to produce 'a human being who is alive, fresh, eager...a total entity' [18]. But an awakening education first of all demands freedom which is necessary to learn, to inquire, to discover, to find out. Krishnamurti is anti-foundationist and hence keeps his education free from all authority. He professes no guru, no book and says: "Not from books, not from philosophers, not from your professors, but to learn from yourself what you are" [19].

Education should essentially 'awaken intelligence' through revolutionary teaching. Krishnamurti himself has been a revolutionary teacher. As Luis S.R.Vas also writes: “As a renowned 'non-Guru', Krishnamurti differs fundamentally from most philosophers in that he has resisted the tendency to weave his insights into a system..." [20]. The aim of Krishnamurti's analysis is "freedom from the Known" [21] which means that that mind which cannot break through the circle of the known is not a free mind. He observes that there can be a finding only when there is no seeking and hence, we should learn as a constant movement without aiming to acquire knowledge.

He engages seriously with the true meaning of knowledge and recommends "the importance of release from entrapment in the 'network of thought' through a perceptual process of attention, observation or 'choiceless awareness' which would release the true perception of reality without mediation of any authority, or guru" [22]. He explains "choiceless awareness" [23] as a function of unconditioned mind. Conditioned mind, he says, cannot learn anything because such a mind is engrossed with words; words tend to describe; description leads to thought; and thought leads to confusion and conflict: "Therefore one has to be free from the word, because the word is not the thing" [24]. He suggests 'total awareness' to avoid such conflicts. By total awareness he means "when you attend completely with your whole being, with your mind, your heart, 
your brain, your nerves, then there is total awareness in which there is no fragmentation as the observer and the observed..." [25] This 'total awareness' can be obtained only through 'absolute freedom' not relative freedom. Absolute freedom wards off all sorts of resistance which is necessary for inward inquiry. He puts: "Look, I want to know myself, I want to know what I am, not according to any religion, any teacher, any philosophy, any analyst, or psychologist. I want to know myself as I am, not as I should be" [26].

The contemporary age of machine and market has no doubt multiplied money and matter but in this marketing expedition human relationship has also become mercantile. Therefore, the educational vision of Krishnamurti becomes very relevant because it aims at bringing about a complete transformation of human consciousness. He therefore asks both the teachers as well as the students to reconsider that what kind of world we are going to live in? He profoundly pronounces that mere intellect cannot resolve the crisis of the modern civilization, and therefore it is necessary to establish in his opinion, "not a theoretical world, not a utopia or a perfect technological world, but a world of human relationship where we can live and function in peace with each other" [27]. His objectives of 'right education' may be aptly summarized in the following views of Elizabeth Lawrence: "The aim of education is a spiritual one, the development of the whole man; attention must therefore be paid not only to the development of intellect, but also to the education of the feelings, the judgment and the creative powers; its purpose is the formation of character, not the development of the brain alone; knowledge is not enough; true education must distinguish between knowledge and understanding, wisdom and instruction; ...each child must be educated according to his individual abilities;...education should be a natural growth, without coercion, forcing or punishment; the right relationship between teacher and children is of fundamental importance" [28].

Krishnamutri motivates us to think that before being doctors, engineers, manufacturers, teachers or officers we are human beings and therefore it is our prime duty to keep humanity alive. He discourages such modern educational institutions that aim at producing only polished professionals who are not more than the mechanical puppets aspiring to roll in money and success. According to him, “...to educate the student rightly is to help him to understand the total process of himself; for it is only that there is integration of the mind and heart in everyday action that there can be intelligence and inward transformation" [29]. This inward transformation has been emphasized again and again by Krishnamurti because he believes that the inner revolution invariably leads to outer mutation. And this cannot be accomplished by any religion, philosophy or science because these are myopic in nature: "Religions have failed, they have not changed man; they have probably given him a little polish. Science hasn't succeeded, nor has any government, party, or philosophy.... Until we do radically bring about a revolution in ourselves, we shall live in war, with violence, with brutality, and so on" [30].

Krishnamurthi's approach is highly comprehensive and integrated. He doesn't confine his educational ideas to mere classroom teaching because that according to him can neither resolve the inner crisis nor transform human consciousness. The objectives of education according to him should be to as follows:

1) It should profess simplicity, love, compassion and fellow feeling,

2) It should discourage bookish knowledge, materialism and authority,

3) It should develop a respectful and sensitive attitude towards the natural world,

4) It should inculcate global outlook which means respect for all because one cannot understand oneself as a separate entity,

5) It should be able to integrate mind, heart and body,

6) It should promote fearlessness and physical, social and mental non- violence.

Thus, it is far more important to inculcate global outlook which means respect for all because one cannot understand oneself as a separate entity.

In order to achieve these objectives of education, Krishnamurti conceptualizes schools in a very different manner. For him, it is a place where we begin to understand the deep significance of human life. It makes us aware of ourselves in our relationship with our children, friends and neighbours. He doesn't approve of education en masse because: "to study each child requires patience, alertness and intelligence" [31]. He is strongly against the unnecessary imposition of learning on the learners and therefore appreciates freewill in the choice of learning subject: "the right kind of education should also help the student to discover what he is most interested in. If he does not find his true vocation, all his life will seem wasted; he will feel frustrated doing something that he does not want to do. If he wants to be an artist and instead becomes a clerk in some office, he will spend his life grumbling and pining away" [32].

He considers that the teachers have a pivotal role to play in the making of man and therefore speaks emphatically on the role of educators. According to him, "An educator is not merely a giver of information; he is one who points the way to wisdom, to truth. Truth is far more important than the teacher.... The true teacher is inwardly rich and therefore asks nothing for himself; he is not ambitious and seeks no power in any form; he does not use teaching as a means of acquiring position or authority, and therefore he is free from the compulsion of society and the control of governments. Such teachers have the primary place in an enlightened civilization, for true culture is founded, not on the engineers and technicians, but on the educators" [33].

\section{CONCLUSION}

Jiddu Krishnamurti stresses on the making of an integrated human being and "to be an integrated human being is to understand the entire process of one's own consciousness, both hidden and the open. This is not possible if we give undue emphasis to the intellect. We attach great importance to the cultivation of the mind, but inwardly we are insufficient, poor and confused. This living in the intellect is the way of disintegration..." [34]. His focus, therefore, is on "dialogue with the self' which is though simple yet not an easy process. 'Truth', according to him, is a 'pathless land' and in order to reach there 'we have to be our own teacher and our own 
disciple'. He emphasizes again and again on "choiceless awareness" because the primary cause of violence and disintegration is our improper way to observe the world, to perceive realty with a conditioned mind, and to learn new things with pre conceived notions. It is a highly effective mode of awareness that first diminishes the separation of time and distance and then yields 'immediate action'. The resulting experience is a state of eternal bliss. Krishnamurti was perhaps the first teacher who said "you have to be your own teacher and your own disciple". It is for this reason that reverend Dalai Lama referred to Krishnamurti as "one of the greatest thinkers of the age", and Time Magazine named him "one of the five saints of the $20^{\text {th }}$ century" [35].

\section{ACKNOWLEDGMENT}

My acknowledgments are to Late Dr. Vijaya Shivapuri, Former Principal, Vasanta College for Women, Krishnamurti Foundation of India, Rajghat, Varanasi, U.P., and to the Krishnamurti Study Center, KFI, Rajghat for introducing me to Jiddu Krishnamurti and his teachings.

\section{REFERENCES}

[1] J. Krishnamurti, Why are You being Educated?: Talks at Indian Universities, Chennai: Krishnamurti Foundation of India, 2002, p. 89.

[2] Ibid, p. 26.

[3] J. Krishnamurti, Education and the Significance of Life, Chennai: Krishnamurti Foundation of India, 1992, p. 11.

[4] J. Krishnamurti, Why are You being Educated?: Talks at Indian Universities, Chennai: Krishnamurti Foundation of India, 2002, p. 122.

[5] Ibid, p. 66.

[6] J. Krishnamurti, Education and the Significance of Life, Chennai: Krishnamurti Foundation of India. 1992, p. 66.

[7] Ibid, p. 66

[8] J. Krishnamurti, Why are You being Educated?: Talks at Indian Universities, Chennai: Krishnamurti Foundation of India, 2002, pp. 101-102.

[9] Ibid, pp. 117-118

[10] R. Powell, "An approach to Krishnamurti," The Mind of J. Krishnamurti, S. R. Vas., Ed. 2003, $18^{\text {th }}$ Impression, Jaico Publishing House, 2007, p. 35.

[11] P. Sheshadri, "Purusharth as an answer to existential crisis," National Seminar on Indian Philosophy: It's Relevance in the 21st Century 18th \& 19th January, [Online]. 2008. Available: www.pvmthane.org/publications, Visited on 17.02.2010

[12] J. Krishnamurti, “On education," Krishnamurti on Education: Talks to Students, Chennai: Krishnamurti Foundation Trust, 2001, p. 11.

[13] J. Krishnamurti, Why are You being Educated?: Talks at Indian Universities, Chennai: Krishnamurti Foundation of India, 2002, p. 11.
[14] R. Mehta, J. Krishnamurti and the Nameless Experience, Bombay, 1973, New Delhi: Motilal Banarasidass Pub. Pvt. Ltd. 1999, p. 58.

[15] J. Krishnamurti, Education and the Significance of Life, Chennai: Krishnamurti Foundation of India, 1992, pp. 97-98.

[16] Ibid, p. 71.

[17] J. Krishnamurti, New Delhi. $2^{\text {nd }}$ Public Talk, Feb 17, 1960. The Collected Works, vol. XI, pp. 355-41.

[18] J. Krishnamurti, Letters to the Schools, vol. 2, 15 ${ }^{\text {th }}$ Nov. 1981, Madras, India, KFI.

[19] J. Krishnamurti, Why are You being Educated?: Talks at Indian Universities. Chennai: Krishnamurti Foundation of India, 2002, p. 123.

[20] Luis S.R.Vas, "J. Krishnamurti: The man and his mind," The Mind of J. Krishnamurti, Ed. Luis S.R.Vas. $18^{\text {th }}$ Impression, Jaico Publishing House, 2007, p. 3.

[21] The learner's mind should be free from all pre-occupations. 'The Known' always yields thought which leads to description and this description yields conflict and confusion.

[22] Luis S.R. Vas, J. Krishnamurti: Great Liberator or Failed Messiah. New Delhi: Motilal Banarasidass Pub. Pvt. Ltd. 2004, p.4. Google Books.

[23] To observe without being an observer.

[24] J. Krishnamurti, Why are You being Educated?: Talks at Indian Universities, Chennai: Krishnamurti Foundation of India, 2002, p. 21.

[25] Ibid., p. 22

[26] Ibid., p. 105

[27] J. Krishnamurti, Why are You being Educated?: Talks at Indian Universities, Chennai: Krishnamurti Foundation of India, 2002, p. 89.

[28] E. Lawrence, The Origins and Growth of Modern Education, Harmondsworth: Penguin. 1970.

[29] J. Krishnamurti, Education and the Significance of Life, Chennai: Krishnamurti Foundation of India, 1992, 2008, p. 46

[30] J. Krishnamurti, Why are You being Educated?: Talks at Indian Universities. Chennai: Krishnamurti Foundation of India, 2002, p. 65.

[31] J. Krishnamurti, Education and the Significance of Life, Chennai: Krishnamurti Foundation of India, 1992, p. 94

[32] Ibid., p. 96.

[33] Ibid., pp. 98-99.

[34] Ibid., p. 67.

[35] As qtd in "Krishnamurti and the star in the East" by Ian Ellis-Jones, [Online]. 2009. Available: fr.slideshare.net

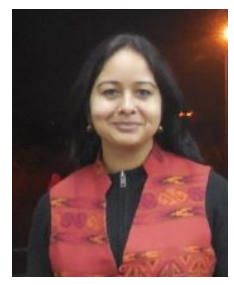

Arti Nirmal is an Assistant Professor in the Department of English at Banaras Hindu University, U.P., India. She earned her degrees of B.A. (English Hons.), M.A. (English), B.Ed. (Gold Medalist), and Ph.D. (English) from the Banaras Hindu University with distinctions and qualified UGC- NET \& JRF in 2005. She has been the recipient of Government of India Scholarship thrice for her academic performance and has also been awarded National Youth Parliament Award, New Delhi; and Vishishta Shikshak Samman (Distinguished Teacher Award), Varanasi. She has authored one book and published numerous research papers in reputed journals. She has presented research papers in national and international seminars and conferences in India and abroad. Her areas of academic interest include literary criticism \& theory, Shakespearean drama, diaspora literature and gender studies. 